\title{
Experimental investigation of open cavity as flame holder of supersonic combustor
}

\author{
Marat Goldfeld ${ }^{1, *}$ \\ ${ }^{1}$ ITAM SB RAS, 4/1 Institutskaya, Novosibirsk, 630090, Russia
}

\begin{abstract}
The results of a study of combustion stabilization in a supersonic combustor for Mach numbers 2, 2.5, and 3 are presented. It was shown that the choice of the fuel injection scheme has decisive influence on the mixing efficiency and flame holding. It has been established that the efficiency of combustion stabilization depends essentially on Mach number and total temperature at the channel entrance.
\end{abstract}

\section{Introduction}

Recent advances in the design of scramjet have shown the technical feasibility of creating and cost-effective application of a hypersonic vehicle. Together with this, the development and testing of the propulsion system is a key problem in the implementation of hypersonic flights. The relevance of such studies is confirmed by national and international programs $[1,2]$. A key element of the scramjet is the combustion chamber with supersonic flow speed at the entrance. Achieving effective ignition and stable combustion in high-speed flows remains a serious problem in designing the combustor. Due to the low static temperature and the incomplete mixing of fuel and air, there is a tendency of the flame to break, even if stabilizers such as a cavity or a backward facing step, artificial ignition with a pilot flame or plasma discharge are used. The problem can be solved by providing the required level of mixing and the corresponding flow structure in front of the flame holder in order to increase the residence time of the mixture in the recirculation region of the flame holder. The aim of the present work was the research of fuel injection and flow structure in an open cavity to ensure self-ignition and stable combustion of kerosene in a relatively short supersonic combustor $(0.4-0.8 \mathrm{~m})$.

\section{Model and facility}

The model consists of an insulator, an injector section and an experimental channel with an expansion angle of $6^{\circ}$ (Fig. 1). Open cavity with ratio $\mathrm{L} / \mathrm{h}=5.5$ was used as flame holder.

Fuel supply was carried out from the top wall of the model. Different schemes were used for fuel injection: into the flow core in front of the step at different angles to the main flow (AI), into the cavity against the flow from the rear wall of cavity(CI) or perpendicular to the flow from bottom wall of cavity (NI). The combination of these ways of injection

\footnotetext{
* Corresponding author: gold@,itam.nsc.ru
} 
allowed studying 6 variants of fuel supply. The system for fuel injection consisted of fuel tanks, pipe lines, locking valves and synchronization system. During the tests, fuel and air flow rates were measured in order to determine the fuel-air equivalent ratio.

Model tests were performed in the mode of attached pipeline. Hot-shot wind tunnel with operation duration of $80-150 \mathrm{~ms}$ which is the effective tool for such research [3] was used as a source of high-enthalpy air. Experiments were made at the following range of flow parameters: Mach numbers at combustor entrance from 2 to 4 , total temperature from $1500 \mathrm{~K}$ to $2700 \mathrm{~K}$, static pressure from $0.06 \mathrm{MПа}$ to $0.25 \mathrm{M \Pi a}$, and equivalence ratio from 0.45 to 1.5. Distributions of static pressure and heat flux on model walls and Pitot pressure at entrance and exit of combustor were measured. Shadow visualization was carried out for the purpose of determining the ignition and position of reaction zones.

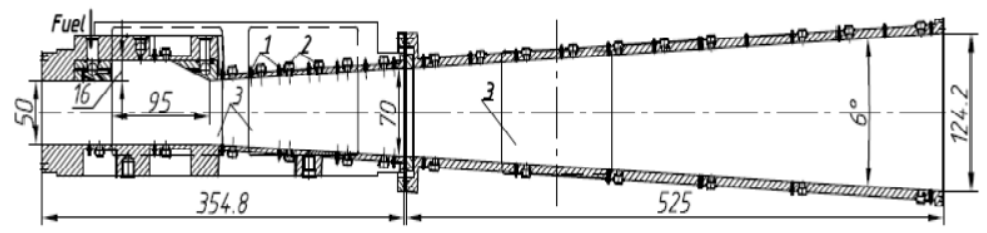

Fig. 1. Model layout: 1- pressure gages, 2-heat flux gages, 3-windows.

\section{Results and discussion}

The initial air temperature at the combustor entrance has decisive influence on the efficiency of ignition. It was found that at total temperature below $1500 \mathrm{~K}$ self-ignition of kerosene does not occur even at Mach number 2, if the kerosene injection was carried out according to the AI scheme. There was only a slight increase of the static pressure and heat fluxes in the channel. The maximum rise (about 50\%) of the parameters was achieved at the initial part of the channel at a length of up to $200 \mathrm{~mm}$. Steady combustion throughout the combustor was obtained at kerosene injection according to the scheme AI +CI (against flow in the cavity) and at an increase of the total temperature up to $2100 \mathrm{~K}$ (Fig. 2).

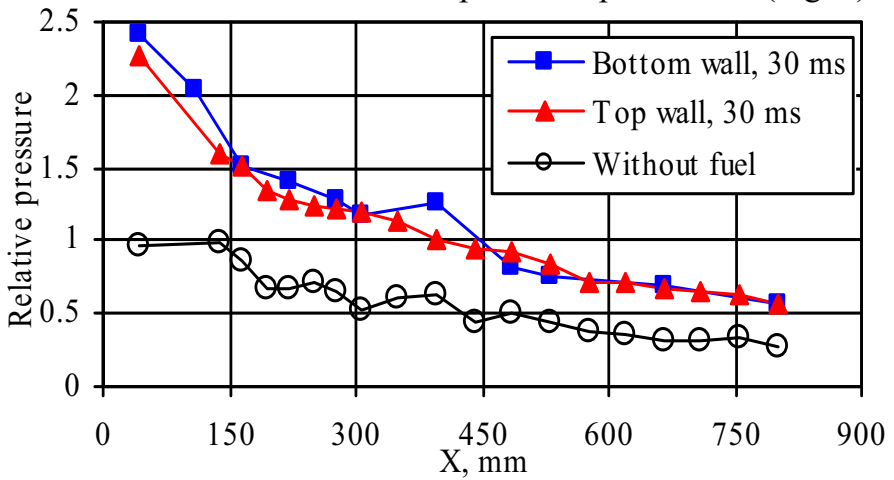

Fig. 2. Pressure distribution at kerosene combustion: $M=2$.

Static pressure increased approximately two to three times along the entire length of the channel and evenly on top and bottom walls. The interaction of the counter jet of kerosene with the air flow led to good spraying and mixing. High temperature behind the shock waves provided self-ignition and stabilization of the combustion process. The results of heat flux measurements (Fig. 3) and flame visualization data confirm the presence of combustion reactions and their intensity throughout the channel volume. Combustion continued for $70 \mathrm{~ms}$. Breaking of combustion occurred as a result of the excessive enrichment of the mixture. At Mach numbers at the combustor entrance of 2.5 and 3, stable 
combustion of kerosene did not occur if the $\mathrm{AI}+\mathrm{CI}$ injection scheme was used. Increasing the total temperature up to $2500 \mathrm{~K}$ did not also lead to intensive combustion due to small residence time of the mixture in cavity.

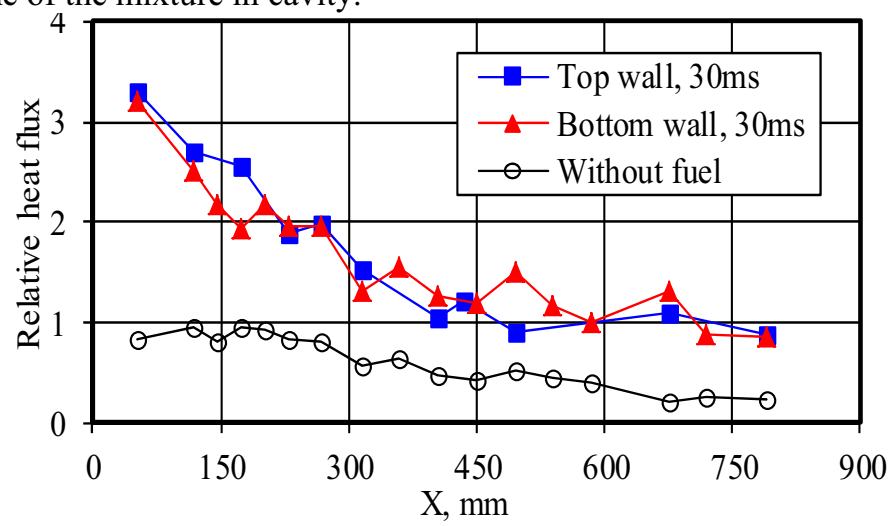

Fig. 3. Heat flux distribution at kerosene combustion: $M=2$.

Therefore, the fuel injection according to the scheme AI + CI + NI (normal injection in the cavity) was tested. The equivalence ratio in the cavity remained unchanged. As a result, intense combustion at Mach number 2.5 was realized and accompanied by a higher increase in pressure than in Mach number 2 (Fig. 4).

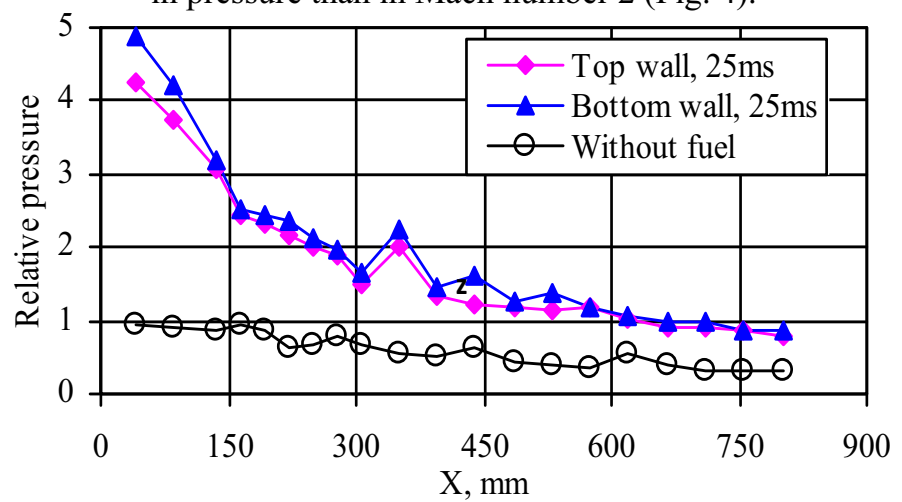

Fig. 4. Pressure distribution at kerosene combustion: $M=2.5$.

The levels of heat flux in the channel walls increased accordingly (Fig. 5). Visualization data in the visible range also confirmed the presence of intense combustion throughout the combustion chamber. It should be noted that the application of the AI + NI scheme at Mach number 2.5 and 3 did not lead to self-ignition of the mixture in the cavity due to the low level of mixing (highly lean mixture).

As a result, the cavity turned out to be ineffective as ignition source and flame holder. In this case, as in the case without fuel supply into cavity, there was slight increase of pressure in the cavity and immediately behind the one, without flame propagation into the flow core.

The intensity of combustion and the efficiency of heat release at Mach number 3 were lower than at Mach number 2.5, despite the increase in the total temperature at the channel entrance up to $2700 \mathrm{~K}$. Therefore, the fuel injection according to AI + CI scheme and with the pylon on BFS before the fuel jets was tested in order to ensure its penetration into the flow core. The use of such injection scheme resulted in sustained combustion of kerosene throughout the entire volume of the channel and significant increase of pressure along the channel length (Fig. 6). 


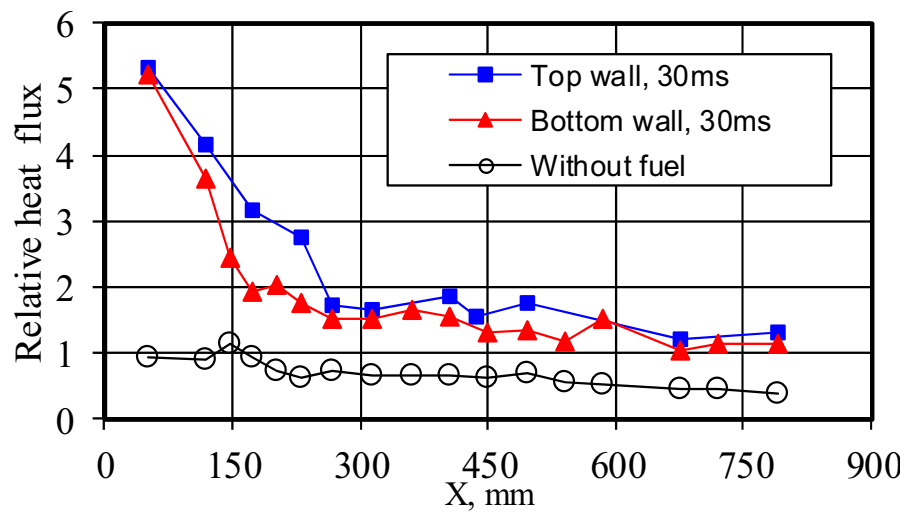

Fig. 5. Heat flux distribution at kerosene combustion: $M=2.5$

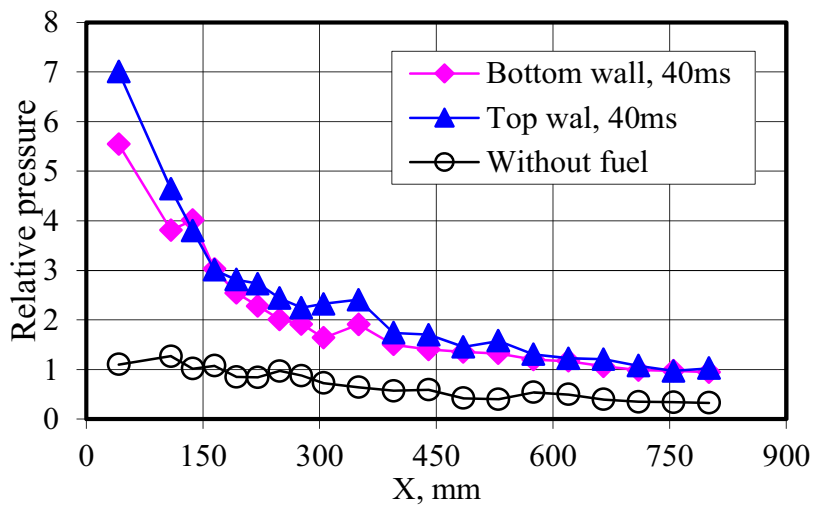

Fig. 6. Pressure distribution at kerosene combustion: $\mathrm{M}=3$.

In the cavity and on the initial section of the channel, the pressure increased more than six times in comparison with the test without fuel. The distribution of heat fluxes in this case had the same features. An increase of fuel-air equivalence ratio was accompanied by a decrease of the duration of supersonic combustion. And then, the transition to subsonic combustion, propagation of the flow disturbance upstream, and channel blocking occurred.

\section{Summary}

Thus, the performed investigations have shown that an open cavity can be used as a source of self-ignition and an effective flame holder. The condition for the efficiency of flame stabilization is the correct choice of the fuel injection scheme, which depends on Mach number and total temperature at the combustor entrance. With an increase in the Mach number, it is necessary to increase the fuel angle injection or (and) use the pylons to ensure fuel supply and efficient mixing in the flow core.

\section{References}

1. J.P. Drummond, AIAA J. 52, 465 (2014)

2. K.R. Jackson, M.R. Gruber, S. Buccellato, J. Propulsion Power 31, 36 (2015)

3. M.A. Goldfeld, A.A. Maslov et al., AIP Conf. Procs. 1770, Paper 030020 (2016) 